Discussion Paper No. 00-02

The Impact of Non-profit Temping Agencies on Individual Labour Market Success in the West German State of Rhineland-Palatinate

Michael Lechner, Friedhelm Pfeiffer, Hannes Spengler, Matthias Almus 


\section{Non-technical summary}

To fight long-term unemployment in Germany, a new promotional program by the German Federal government started in October 1994 - "Guidelines for the promotion of reintegrating the hard-to-place unemployed by means of loans and subsidies to Temporary Employment Agencies". The programme that was limited to the period from 10/01/94 to 12/31/96, aimed at integrating unemployed people with reintegration difficulties into the primary labour market. The subsidies granted by the programme resulted in an increased trend towards "non-profit temping", which on the one hand led to the formation of new non-profit temp agencies and on the other hand led to an extension of the activities of a number of existing non-profit organisations.

Institutions engaged in "non-profit temping" have the explicit aim of facilitating the reintegration of unemployed into the primary labour market. To achieve this, they employ previously unemployed people and hire them out to other firms (borrowers) for a fee. While commercial lenders are generally not interested in losing good workers to the borrowers, the "non-profit temping" represents a new instrument linking the labour lending activity with the aim of reintegration into the primary labour market. Ideally, the temp worker will be hired permanently by the customer of the temp agency (borrower) and thus reintegrated into the primary labour market.

The paper presents an econometric assessment of the effects of non-profit temporary employment agencies in Rhineland-Palatinate on individual labour market success. That is, the paper focuses on the question whether previously unemployed people, who were employed by a non-profit temp agency, show a higher rate of reintegration into the primary labour market than without ,non-profit temping“. It is based on data of the German Federal Employment Services made available from files for computer-assisted job brokering. Using the computer-assisted job brokering-data and econometric matching methods, a control group of unemployed workers is selected that resembles the group of temporary workers in terms of their socio-economic structure and labour market history.

The econometric comparison of the reintegration success reveals differences between temporary workers and control group. In our observation window (up to 5 months after leaving a temp agency), the reintegration success of temp workers was significantly higher than that of the control group. For example, two months after leaving the temp agencies, $27.4 \%$ of the temp workers were employed in the primary labour market compared to only $11.3 \%$ in the control group of non-temps after the same period. Furthermore temp workers stay approx. 15 days longer in the labour market within the first four months after leaving the temp agency. 
For a comprehensive evaluation of the programme in question, more extensive analyses would be required that should include other direct impacts (for example on earnings; on longer term impacts; on participants' reduced use of social welfare etc.), indirect impacts (for example, on non-participants and through the forgone use of the money invested) and the longer perspective of the non-profit temp agencies in the evaluation. This task, however, is closely related to the need of better data. 


\title{
The Impact of Non-profit Temping Agencies on Individual Labour Market Success in the West German State of Rhineland-Palatinate*
}

\author{
Michael Lechner ${ }^{+}$, Friedhelm Pfeiffer ${ }^{++}$, \\ Hannes Spengler ${ }^{++}$, Matthias Almus ${ }^{++}$ \\ ${ }^{+}$SIAW, University of St. Gallen, Switzerland \\ ${ }^{++}$Centre for European Economic Research (ZEW), Mannheim, Germany
}

Michael Lechner

University of St. Gallen/ SIAW-HSG

Duffourstr. 48/ 9000 St. Gallen/ Switzerland

+41712242814 (phone)

+41712242298 (fax)

michael.lechner@unisg.ch

http://www.siaw.unisg.ch/lechner
Friedhelm Pfeiffer, Hannes Spengler, Matthias Almus

Centre for European Economic Research (ZEW)

L 7, 1/ 68161 Mannheim/ Germany

+49 $6211235150,284,185$ (phone)

+496211235225 (fax)

pfeiffer@zew.de, spengler@zew.de, almus@zew.de http://www.zew.de

\begin{abstract}
The paper presents an econometric evaluation of the effects of subsidised non-profit temporary employment agencies - a programme of the West German active labour market policy - on individual labour market outcomes. The empirical analysis is based on individual data from files for computer-assisted job brokering in Rhineland-Palatinate. Econometric estimates based on matching methods suggest that the programme generated a statistically significant additional reintegration success of about 13 per centage points. Furthermore within the first four month after leaving the programme, the estimated effect was about half a month additional employment for the participants.
\end{abstract}

Keywords: Econometric evaluation methods, matching, active labour market policies, temporary employment agencies

JEL Classification: C52, J64, J68

* The first author gratefully acknowledges financial support from the Deutsche Forschungsgemeinschaft (DFG, grant 928/2) and the Swiss National Fund (SNF, grant 121453735). The paper results from a project commissioned by the Institute for Employment Research of the Federal Employment Services (IAB-Projekt 10-483 A) and the Ministry for Labour and Social Affairs of the German Federal State of Rhineland-Palatinate. We thank Christian Brinkmann and Doris Bartelmes for valuable comments and support. Karl John and Karl Schäfer helped us to understand the complex public files for computer-assisted job brokering. Thanks also to Jürgen Egeln, who joined the project and to Martin Eichler for carefully reading a previous version of this manuscript. 


\section{Introduction}

To fight long-term unemployment in Germany, in October 1994 a new promotional programme by the German Federal government started - "Guidelines for the promotion of reintegrating the hard-to-place unemployed by means of loans and subsidies to Temporary Employment Agencies" (GPTA). The programme that was limited to the period from $10 / 01 / 94$ to $12 / 31 / 96$, aimed at integratipg unemployed people with reintegration difficulties into the primary labour market. ${ }^{b}$ The subsidies granted by the programme resulted in an increased trend towards "non-profit temping" $(N P T)$, which on the one hand led to the formation of new non-profit temp agencies (NPTAs) and on the other hand led to an extension of the activities of a number of existing non-profit organisations. In this paper we assess the direct impact of these NPTAs on individual labour market success. That is the paper focuses on the question whether previously unemployed people who were employed by a NPTA show a higher rate of reintegration into the primary labour market than without $N P T$.

Institutions engaging in NPT have the explicit aim of facilitating the reintegration of unemployed into the primary labour market. To achieve this, they employ previously unemployed people and hire them to other firms in return for a fee. While commercial lenders are generally not interested in losing good workers to their customers, the NPT represents a new instrument linking the labour lending activity with the aim of reintegration into the primary labour market. Ideally, the temp worker $(T W)$ will be hired permanently by the customer of the temp agency and thus reintegrated into the primary labour market.

This new instrument of active labour market policies $(A L M P)$ is related to two general developments in Germany. One was the further rise in unemployment and especially long-term unemployment after the recession in 1992/93, the other, deregulation of labour market institutions. Specifically, the so-called "placement monopoly" of the Federal Employment Services (FES) was abolished in 1994.

1 "Richtlinien zur Förderung der Eingliederung schwervermittelbarer Arbeitsloser durch Darlehen und Zuschüsse an Gesellschaften zur Arbeitnehmerüberlassung, $A \ddot{u} G R i$ ".

2 In Germany "A person is considered hard-to-place (have integration difficulties) when one or more hindrances to placement exist, e.g. serious disability, a lack or a low level of vocational qualifications, age (usually at least 50 years old), health-related limitations, a longer period of unemployment (at least one year) or personal reasons on part of the job seeker." (Walwei, 1998: 20). The terms hard-to-place or hard-to-employ are not used internationally in a similar way; see for concepts and problems with this terms Erhel et al. (1996). 
Furthermore some rather restrictive regulations in the legal framework of temporary employment agencies have been relaxed.

There is a rich literature on evaluations of $A L M P . \mathrm{A}$ large part of this literature deals with the impact of publicly financed training or employment providing programmes. A policy programme comparable to the German one investigated here has, to the best of our knowledge, not been in use in another country. While the details of NPT appear to be rather unique, from its aims and procedures, it can at best be compared to programmes that aim at providing temporary work experience (work habit) for disadvantaged persons. The main difference is that these programmes usually do not subsidise agencies. Instead they subsidise the wages of the disadvantaged or provide temporary jobs in public or private firms. In the U.K. the "Employment Action" programme provides participants with subsidised employment in non-profit or public sector jobs. This programme had an estimated net effect of $4 \%$ on employment rates (Heckman, LaLonde and Smith, 1999: Table 10.7). In France, the "Travaux d'Utilité Collective" had a positive short term impact on the probability of finding a new job for young, lower skilled people (Bonnal, Fougère and Sérandon, 1994, 1997).

The structure of this paper is as follows: In section 2 the general concept of temp agencies is explained in greater detail, followed by a description of the characteristics of the respective NPTA under consideration. Section 3 discusses the special characteristics and problems associated with the data. Section 4 contains

3 For recent surveys see Friedlander, Greenberg and Robins (1997), Heckman, LaLonde and Smith (1999) and OECD (1996).

4 See for Germany Eichler and Lechner (1998), Kraus, Puhani and Steiner (1997) as well as Lechner (1999a) and the literature cited therein.

5 Maybe with the exception of the Netherlands, where a public NPTA was founded called START (see de Koning, Denys and Walwei, 1998), which has become commercial now. We are not aware of an econometric evaluation of START. Job placements according to the so-called "Maatwerk"-method in the Netherlands have comparable aims. Commercial agencies get premia for a successful placement. This method has also recently (January 1998) been introduced in Germany for the hard-to-place persons and lasts currently until the end of 1999.

6 This belongs to the second group of five policies discussed in Heckman, LaLonde, and Smith (1999: 15), called "subsidized employment with public or private employers". A comparison with the results of evaluations of US-programmes is however difficult, because these studies are as a rule more interested in income or wage effects. For an overview and discussion of policy measures designed for hard-to-place persons cf. Erhel et al. (1996).

7 Examples of direct public job creation programmes: "Arbeitsbeschaffungsmaßnahmen" in Germany, "Employment Action" programme in the United Kingdom since 1991, "Travaux d'Utilité Collective" in France, cf. Erhel et al. (1996). 
methodological considerations and explains the econometrics. The results are discussed in section 5. Section 6 summarises and concludes. The Appendix gives some additional information on how the information in the coArb is turned into a data set that can be analysed by econometric methods.

\section{The Concept of Non-profit Temp Agencies in Germany}

\subsection{Temping agencies in Germany}

The terms "temp work", "labour lending" and "personnel leasing" refer all to a mode of employment that differs in one central aspect from standard employment. While standard employment can be understood as a relationship between two parties (employee and employer) in which a working and employment relationship coincide, the hiring out of labour is a trilateral concept (employee, lender and borrower) in which the working relationship and the employment relationship are separated (for more details on the institutions see Almus et. al., 1999). In the temp work business, it is the temping agency that acts as the employer having a contract with the $T W$. The lender hires out his $T W$ for "use" to a third party - the borrowing enterprise. Terms and conditions of this hiring out (hiring out duration, fee etc.) are specified in a lending contract. The attractiveness of providing temporary work for the agency lies in the lending fees payable to it. The borrower saves personnel costs for various reasons.

In Germany this sector is regulated by the Law on Labour Lending. This legislation permits hiring out of employees because it is expected that several temporary or limited working relationships with borrowing enterprises lead to extended or even permanent employment. As the majority of temp agencies in Germany are run by commercial enterprises (see Walwei, 1998), the initial aspirations of the legislation regarding reintegration of temporary employees into normal employment relationships were not fulfilled. Commercial temp agencies are not interested in losing their good-performing employees to their customers since these goodperforming $T W s$ are the basis for the economic success of the agency.

Due to the constant high unemployment in the nineties, the original form of employee hiring out was rediscovered and modified as a policy instrument. The already implicit objective of temp agencies, the brokering of labour, was now made the explicit aim of a new model of reintegration-oriented employee hiring out. The aim is two-fold: Firstly, by being hired, unemployed people should get reaccustomed to work. Secondly, enterprises should be encouraged to provide opportunities to those unemployed people who belong to problem groups. The possibility to employ members of these groups risk-free and without any legal commitment, i.e. reversible at any time, shall give decision-makers in companies a 
comparatively cheap opportunity to find out both the potential and capabilities of these unemployed people for themselves. When the temp agency generates profits, those profits should be used for further education and training of the $T W s$ in times when they are not hired out.

GPTA was supported with 51 million German Marks by the federal government limited to the period 1994 to 1996 . The funds were granted as subsidies or interestfree loans and exclusively accessible to those temping agencies that committed themselves that at least a quarter of their $T W s$ were hard-to-place unemployed. GPTA was not only directed towards existing commercial agencies. Other corporations could also engage in lending of $T W s$, e.g. incorporated associations and non-profit agencies that comply with the required prerequisite of reintegration problems can be eligible for subsidisation. When the guidelines took effect there were about 65 NPTAs in Germany. Then the sector expanded in form of start-ups and extension of the business of already existing non-profit organisations. The total number of companies subsidised by the GPTA programme in Germany was 105, of which 90 were non-profit organisations. The strong majority of non-profit organisations suggests that the programme raised only little interest with commercial agencies.

\subsection{The agencies under investigation}

In this study the work of eight NPTAs in Rhineland-Palatinate are examined (see Table 1). Information on the agencies is based on an analysis of a written survey and on comprehensive interviews, which we conducted with representatives of each agency. Regarding the concept of the project and the organisation and design of the contractual relationships with the customers and $T W s$, there are differences between the agencies with respect to the size of the agency, the proportion of people with reintegration problems and the coverage of costs resulting from lending activities. The number of employees in the agencies ranges between 24 and 243 TWs during the two years under investigation.

The agencies were only subsidised by the GPTA programme if at least $25 \%$ of their employees (respectively unemployed) fulfilled the criterion of having reintegration

8 An important reason for this is certainly the different treatment of both types of agencies. While NPTAs received subsidies, commercial agencies were usually only granted interest-free loans that could partly be transformed into subsidies for those $T W s$ with reintegration problems becoming permanently employed with the borrowers (see Vanselow and Weinkopf, 1997). However, this way of support appeared not to be sufficient to stimulate commercial temp agencies to increase the share of unemployed with reintegration problems. 
problems. Of course, this criterion was met by all agencies used for this study. In fact the share was between $34 \%$ and $96 \%$.

At the reference date on 12/31/96 (end of public GPTA-support), 211 TWs were still employed by the companies. 219 of 832 were employed, 317 were unemployed immediately after the end of the programme; of the remaining participants, three worked as self-employed, 29 entered a qualification programme (re-education, further education etc.), one person has been receiving old-age pension, and the status of 52 people is unknown.

Table 1: NPTAs in the regions of Rhineland-Palatinate: number of TWs, share of problem groups and labour market indicators

\begin{tabular}{lccccc}
\hline Region/ city & TWs & $\begin{array}{c}\text { Problem group } \\
\text { NPTA }\end{array}$ & & Unemployment & \multicolumn{2}{c}{ Unemployment rate } \\
\cline { 5 - 6 } Speyer & 243 & 34 & 1996 & 1996 & 1994 \\
Ludwigshafen & 82 & 72 & 3350 & 8.2 & 7.3 \\
Frankenthal & 155 & 54 & 9460 & 9.4 & 8.4 \\
Simmern & 198 & 68 & 2953 & 9.7 & 8.0 \\
Trier 1 & 63 & 51 & 2685 & 11.1 & 10.1 \\
Trier 2 & 42 & 81 & 5911 & 10.0 & 8.9 \\
Boppard & 24 & 96 & 1245 & 7.8 & 6.8 \\
Koblenz & 25 & 84 & 4774 & 8.3 & 7.0 \\
\hline Rhineland-P. & 832 & 67 & 149,781 & 9.4 & 8.4 \\
\hline
\end{tabular}

Source: ZEW, Amtliche Nachrichten der Bundesanstalt für Arbeit (different issues), own calculations; * hardto-place unemployed as share of all TWs at respective NPTA.

Between 1995 and 1996 the NPTAs received 3.2 millions German Marks in subsidies for staff and equipment from the Federal Employment Services. Table 1 shows that the size of the activities of the NPTAs compared to the number of unemployed in the regions where they are operating is rather small. That is true, even if one restricts the comparison to the group of hard-to-place persons, which is roughly about one third on average.

Regional unemployment rates differ due to differences in the industrial composition and the socio-economic structure of the workforce. Unemployment rates have risen during the observation periods in all regions, indicating job losses in the industry as

9 See Almus et al. (1999). A higher proportion of unemployed with reintegration difficulties results in higher costs of finding jobs and less frequent hiring out. The contributions from the hiring out activities covered between $35 \%$ and $93 \%$ of the costs running the temp agency. The cost share is negatively correlated with the number of unemployed with reintegration difficulties. When the funds from GPTA were no longer available, agencies tried to rise the proportion of coverage from hiring out activities. 
well as a rise in the supply of workers, mainly due to immigration from East European countries.

\section{Data}

\subsection{Introductory remarks}

The econometric assessment of the reintegration success is based on the group of $T W s$ and a non-experimental comparison group of unemployed not participating in a temp agency, drawn from the computer-assisted job brokering data (called "coArb" for four regional departments of the FES (called "employment office districts"). The data include all unemployed with respect to the reference day 12/31/96 (the day at which coArb-data were extracted), from the employment office districts of Koblenz, Bad-Kreuznach, Ludwigshafen, and Trier, where all NPTA under investigations are located.

For the purpose of assessing labour market policies, comprehensive information on labour market relevant characteristics is needed that is fully available for both the programme participants (the $T W s$ ) and the non-participants (the comparison group). In view of these requirements, the use of the coArb as database for an evaluation of the reintegration-oriented hiring out of employees has the following advantages: Since most $T W s$ were registered as unemployed before the programme started, it was possible to find them in the coArb by a comparison with the information resulting from the interviews at the agencies, e.g. name, date of birth. At the same time, all other unemployed people registered in the coArb-database can be used as potential comparison observations. Thus, we have a uniform basis of information for both $T W s$ and comparison group.

coArb contains standard information on personal characteristics and skills. It also contains the following information on employment histories of registered unemployed and employment seekers, mostly stating daily dates:

- Earlier employment relationships (information on the job performed and the employer);

- Periods of previous unemployment, illness and some other events;

- Participation in other programmes of $A L M P$;

10 The coArb is used in all 181 German employment office districts in a standardised, but decentralised form. With the exception of the information on job openings, typically, the data used in one employment office district is not accessible beyond its borders. The offices within employment office districts are linked, however. 
- Reporting failures ("Meldeversäumnisse") by the unemployed (unemployed have to come to the office on a regular basis, otherwise it is a reporting failure);

- Periods in which the employment office had no information on the whereabouts of the registered person.

The use of the coArb has also its limitations that stem from the way the data base is managed. For example after the termination of the "reactivation period", which starts with the day of unregistration from the coArb ${ }^{\omega}$ and generally lasts 10 month, the data of the observed person will automatically be deleted by the computer system. People having entered a programme earlier than 10 months before the reference day and who do not register with the employment office again, cannot be found any more in the coArb. In contrast $T W s$ who have entered a NPTA earlier than 03/01/96 and who become unemployed again within the 10 months preceding the reference date, can be found in the coArb.

Thus, the possibility of finding a person in the coArb is closely tied to the successful reintegration of that person. In order to prevent a distortion of the evaluation of the reintegration success by (negative) selection effects, the analysis is restricted to those $T W S$ who entered the programme not earlier then 10 month before the reference day. A further problem of the $c o A r b$ is that due to its customisation for the requirements of the labour brokering, numerous information are only available in the form of unencoded data, i.e. in the form of text fields. This affects primarily the data on the employment history that are of special importance for the formation of comparison groups. To make these data usable for a statistical analysis requires a non-automatic and thus time-consuming reorganisation.

Apart from legal restrictions due to data protection laws in Germany, the above mentioned difficulties are probably the main reason why the coArb has hardly been used so far for scientific purposes, although it is in many respects superior to the data typically used for econometric evaluations in Germany.

\subsection{The selection of the sample}

When questioning the agencies, information on $832 \mathrm{TWS}$ were collected. From these, 134 people were suitable for an estimate of their reintegration success. The

11 Unregistration from the coArb is carried out when the unemployed finds a job or the way into a NPTA. Apart from that there is a great number of other reasons for an unregistration, e.g. a second reporting failure, illness, entering further education or leaving the labour market. The unregistration of applicants that reregister with the employment office within the reactivation period are deactivated. 
reasons for this reduction are the following: Only those $T W S$ can be included into the evaluation for whom information from the coArb database can be used. For 227 people this is not the case, because they are either not from one of the four employment office districts whose coArb data were available for this study (70), or because they were deleted from the database after expiration of their reactivation period (67), or because they were not registered at the employment office at all and obtained their employment with an agency in another way (90). In addition the part of the coArb database of the employment office district of Koblenz containing the information on the employment histories is not available (23). Therefore all further analyses are based exclusively on the coArb data of the employment office districts of Bad-Kreuznach, Ludwigshafen, and Trier. 582 TWs remained. These people could be traced in the regional coArb database by comparing their name and date of birth with the information from the questionnaire.

Judging from the standard 10-month reactivation period persons who entered employment with an agency earlier than 10 months before the reference day, only those could be found in the coArb database who were recorded again at the employment office after $02 / 29 / 96$, i.e. who had become unemployed again. However, those $T W S$ that had directly entered the primary labour market after their employment by a temp agency and stayed there could no longer be traced. Unemployed having entered their employment relationship with a temp agency before the 03/01/96 which can be found again in the coArb database as per 12/31/96 are therefore likely to be systematically less successful in their reintegration into the primary labour market. If this consideration is not taken into account, there will be the danger of underestimating the effect of the programme.

Even in the event that TWS who were employed by an agency earlier than the 03/01/96 and passed into the primary labour market after leaving the agency could be found again in the coArb database, their inclusion into the evaluation would not be advisable, because it is not possible to trace potential comparison group members in the coArb entering the primary labour market before 03/01/96 and remaining there beyond 12/31/96. Thus the estimated effect of the programme could be positively biased.

The mentioned selection problems created by the 10-month period are circumvented by the limitation of the sample to people who entered the programme after 02/29/96. If it is also taken into account that the reintegration effect can only be determined for completed programmes, and that the unemployed must therefore have left the agency before the $12 / 31 / 96$, the sample reduces to 175 observation.

In the last step, unemployed are excluded who are younger than 18 or older than 53 years. This is done partly to restrict the survey to adults, and partly to exclude 
people whose participation may be directly linked to early retirement. Furthermore, those people are excluded with two or more independent stays in an agency, or with a stay of less than eight days. Very short stays are rarely accompanied by sustainable effects and several independent stays should be analysed separately, which is not possible due to a lack of cases. This last step reduces the number of observations to 134 .

The limitation of the sample to people having been employed by an agency between the $03 / 01 / 96$ and the $12 / 31 / 96$ in order to avoid selection-related distortions might be achieved at the cost of a new potential selection problem. Less successful $T W s$, who entered a NPTA after the 03/01/96 and stayed there beyond 12/31/96 are excluded from the analysis, with the possible consequence of the reintegration success being overestimated. We regard this distortion as minor, because the duration of the employment with an agency as such is not an indicator for a later success of the $T W$ in the primary labour market. Both for short and for long-term programmes, there is a positive as well as a negative interpretation of their relationship with the further employment history. Short stays may be due either to a quick transition of the $T W$ to the primary labour market, but also to a dismissal of the $T W$ by the agency (e.g. unsuitability of the $T W$ or a lack of appropriate demand by customers). Long-term stays can either be the consequence of difficulties to reintegrate the $T W$ into the primary labour market or be due to the fact that an agency holds on to a person who is a valuable contribution to business success.

\subsection{Descriptive analysis}

The participation in active labour market programmes is not accidental. On the one hand such programmes are targeted explicitly towards specific (problem) groups. In the case of the NPT it is particularly the group of unemployed with reintegration difficulties that is intended to be supported. On the other hand, only some of the people being eligible actually participate.

The comparison of the mean values of selected socio-economic and demographic characteristics between the TWs and the pool of all persons registered in the coArb highlights striking differences (cf. Table 2). The second column shows descriptive statistics for the "population", i.e. 144,002 unemployed or employment seekers registered in one of the three employment office districts as per 12/31/96. The third column contains descriptive statistics for $582 \mathrm{TWS}$ found in the databases, and the fourth column lists the $134 \mathrm{TWs}$ forming the basis for the estimation. The selection of the characteristics shown in Table 2 is made according to the relevance of the respective variable for the evaluation and according to whether the information is already available in encoded form in the coArb database. 
In comparison to all unemployed, $T W s$ are younger, more often male and severely disabled but less frequently with impaired health, more often foreigners and more often former expatriate Germans relocated from Eastern Europe. Regarding the level of schooling and vocational training, TWs turn out to be skilled below average. These numbers seem to be consistent with the promotional concept customised for unemployed with reintegration difficulties. Despite some deviations between columns 3 and 4 of Table 2 for the variables "single", "foreigner", "relocated expatriate" and "unskilled worker", that may be attributable to random sampling error, both samples of $T W s$ appear to be more or less similar.

Table 2: Descriptive statistics of selected variables for three samples

\begin{tabular}{|c|c|c|c|}
\hline Samples & CoArb & $\begin{array}{l}\text { TWs found in } \\
\text { coArb }\end{array}$ & Selected TWs \\
\hline Observations & 144,002 & 582 & 134 \\
\hline Variables & $\begin{array}{c}\text { Mean (std) } \\
\text { or share in \% }\end{array}$ & $\begin{array}{c}\text { Mean (std) } \\
\text { or share in \% }\end{array}$ & $\begin{array}{c}\text { Mean (std) } \\
\text { or share in \% }\end{array}$ \\
\hline Age & $37.9(12.8)$ & $35.6(10.3)$ & $32.8(9.3)$ \\
\hline Gender (male) & 60.1 & 77.5 & 77.6 \\
\hline \multicolumn{4}{|l|}{ Marital status } \\
\hline single & 37.4 & 38.7 & 44.0 \\
\hline not single & 9.7 & 11.4 & 6.0 \\
\hline married & 52.1 & 49.6 & 50.0 \\
\hline single parent & 0.8 & 0.3 & 0.0 \\
\hline Number of children & $0.4(0.9)$ & $0.6(1.0)$ & $0.5(0.9)$ \\
\hline Severely disabled & 5.3 & 7.0 & 6.7 \\
\hline With impaired health & 27.1 & 21.5 & 22.4 \\
\hline $\begin{array}{l}\text { With impaired health influencing the reintegration } \\
\text { success }\end{array}$ & 15.3 & 11.2 & 11.9 \\
\hline Foreigner & 10.9 & 12.2 & 17.2 \\
\hline Relocated expatriate from Eastern Europe & 5.9 & 16.0 & 12.7 \\
\hline \multicolumn{4}{|l|}{ Schooling / degree } \\
\hline secondary school (9 years), no degree & 11.7 & 17.3 & 17.9 \\
\hline secondary school (9 years) & 63.0 & 65.6 & 62.7 \\
\hline O-levels (10 years) & 13.5 & 10.0 & 11.2 \\
\hline $\begin{array}{l}\text { A-levels or qualification for vocational } \\
\text { college (more than } 11 \text { years) }\end{array}$ & 11.8 & 7.1 & 8.2 \\
\hline \multicolumn{4}{|l|}{ Vocational training / degree } \\
\hline No degree & 45.4 & 52.7 & 54.5 \\
\hline Apprenticeship & 45.4 & 41.7 & 39.6 \\
\hline Vocational school & 4.3 & 3.3 & 2.2 \\
\hline Vocational college / polytechnic & 1.5 & 0.9 & 0.7 \\
\hline University & 3.4 & 1.5 & 3.0 \\
\hline Desired occupation on 2-digit-level ${ }^{*}$ & $61.4(24.7)$ & $51.7(24.4)$ & $52.3(22.3)$ \\
\hline \multicolumn{4}{|l|}{ Occupation in last employment } \\
\hline unskilled worker & 22.5 & 36.8 & 50.7 \\
\hline skilled worker & 13.6 & 10.9 & 7.5 \\
\hline clerical staff & 18.6 & 6.6 & 5.2 \\
\hline others & 45.3 & 45.8 & 36.6 \\
\hline \multicolumn{4}{|l|}{ Employment office district } \\
\hline Bad Kreuznach & 31.2 & 23.7 & 13.4 \\
\hline Ludwigshafen & 32.9 & 59.6 & 64.2 \\
\hline Trier & 35.9 & 16.7 & 22.4 \\
\hline
\end{tabular}

Source: coArb Bad-Kreuznach, Ludwigshafen and Trier; own calculations. ${ }^{*}$ This is not a metric variable. 
While the variables listed in Table 2 are contained in encoded form in the coArb database, the information on the employment histories are available only in the form of text entries (cf. Table A1) that are not suitable for automated processing without losing too much information. As employment history data are crucial for the evaluation exercise, a manual processing of that data was carried out.

For the purpose of using these day specific information in the econometric estimation in an operational way, a time framework was used that was put together from 61 reference dates of the observation period from 12/31/89 to 12/31/96 (cf. Table A2). The distance between the reference dates increases with the distance from $12 / 31 / 96$, so that the more recent employment history is more precisely recorded. The idea is that the more recent history is a more important component of the selection process into NPT than the more distant past (see Appendix for more details).

Time is measured in "half-months". The range of values of the initial and the final date of the programme is restricted to the half-months 1 to $19(03 / 01 / 96$ to $12 / 31 / 96$, cf. Table A2) and the range of values of the duration which the unemployed stayed in the programme to 19 half-months. The first $T W s$ entered the programme before 03/16/96; the last entries took place after 12/16/96. The earliest exits took place between the $16^{\text {th }}$ and the $29^{\text {th }}$ of April 1996. The latest exits were observed between the $16^{\text {th }}$ and the $31^{\text {th }}$ of December $1996.90 \%$ of the participants observed entered the programme before 10/16/96 and ended it before 12/16/96. 90 $\%$ of the participants can therefore be observed at least two half-months after the end of their participation. Half of the participants can be observed up to eight halfmonths after leaving the programme.

Approximately $70 \%$ of the employment relationships with temp agencies have lasted no more than three months, and about $90 \%$ had a duration of up to 10 halfmonths (cf. Figure 1). The sharp decline of the employment duration in the first half of the observation period indicates that the NPT is not designed as a permanent employment relationship, but as a transitional solution. All statements on the success of NPT refer to the short period of two up to ten half-months after the termination of the employment relationship with the temp agencies. Further statements on medium- and long-term effects are not possible.

Figure 2 reveals information about the employment status of the $T W s$ before and after the programme. The upper part of the figure depicts the development of the percentage of unemployed, in the lower part that of the employed. In view of the fact that participation in NPT is generally linked to prior unemployment it comes as no surprise that the proportion of the employed NPT one period before the start of the programme lies at $0 \%$ and the respective proportion of unemployed lies at 
almost $100 \%$. Striking is the sudden downward bend of both graphs by $10 \%$ each immediately before the start of the programme. An explanation may be that the labour administration wants to help especially new entrants into unemployment to find quickly a new job.

Figure 1: Duration of stay in NPTA

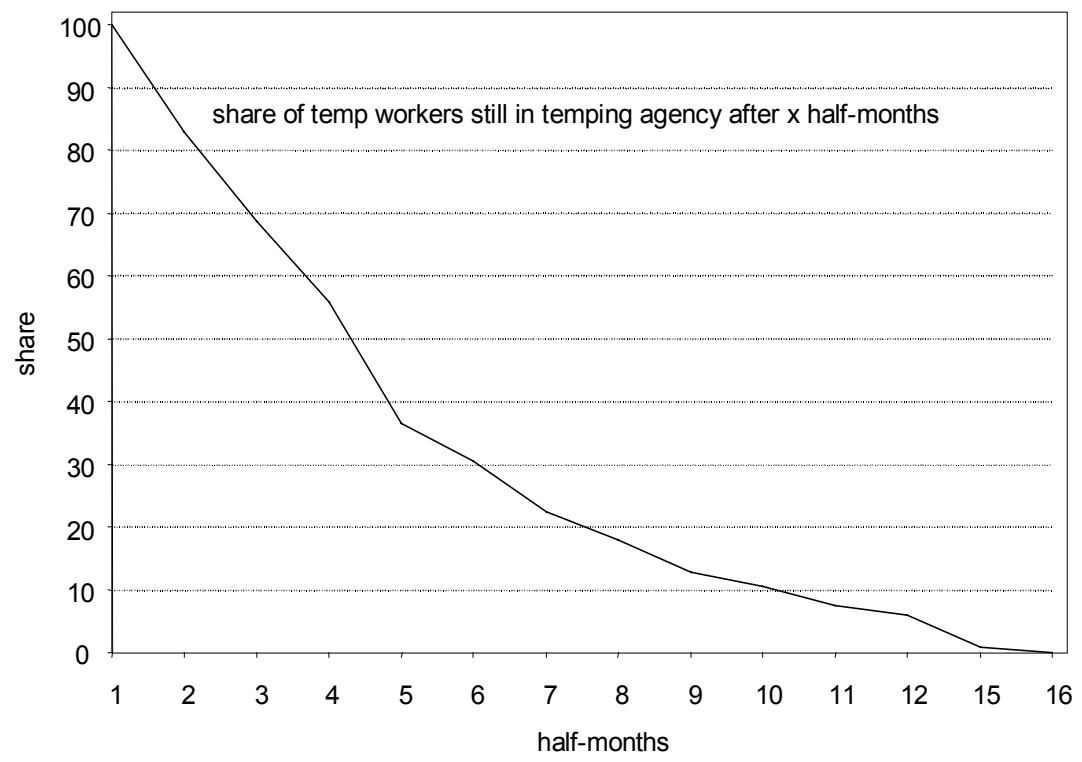

Source: Own calculations based on the processed employment histories.

After leaving the NPTA, $18.7 \%$ of the TWS were employed, corresponding to the level of 10 half-month periods before entering the programme. The share rises to a level of more than $25 \%$. While the result of one period after leaving the NPTA is based upon all 134 observations, in period 5 only 100 people are observed. In period 7 finally it is 75 and in period 10 - that is 10 half-months after the respective termination of the programme - 38 people are left. Blaschke and Nagel (1995) calculated 3-4 month reintegration rates after training programmes according to the Law on the Promotion of Employment ("Arbeitsförderungsgesetz") in the old German federal states of $46.5 \%$ that are higher than in our study. One is tempted to say that the new programme is less successful than the traditional training programmes.

However, such a conclusion based on the so-called "Before-After-Comparison" is premature because it does not take into account potential peculiarities of the respective groups of participants. To get a better estimate of the effect of this programme, we select a comparison group of unemployed from the coArb who have not been employed by a NPTA so far, but are otherwise as similar as possible to the TWs. 
Figure 2: Employment status of $T W s$ before and after their stay in NPTA

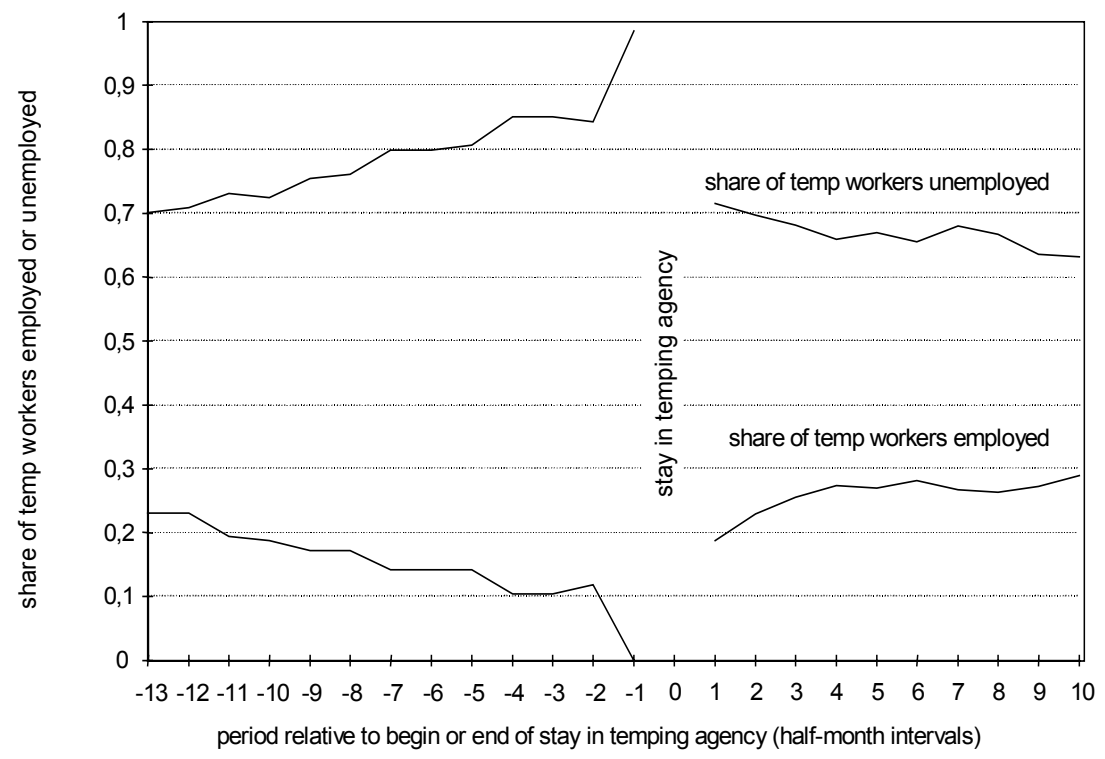

Source: Own calculations based on reorganised and processed employment histories.

\section{Econometric evaluation of the reintegration success}

\subsection{Methods of evaluation}

The method to be used for an evaluation depends among other things on the data available. If the data stem from a social experiment, the demanded comparability of participants in the programme and non-participants is given by the design of the experiment. Then, the average causal effect of the programme can be estimated as the difference of the target values between the group of participants and the randomised non-participants.

In a non-experimental setting participants might differ systematically from the group of potential comparison observations. However, these differences are correlated with the participation success due to "self-selection" or "programme selection". Two ways to get an undistorted effect of the programme have been proposed in the literature: The so-called parametric method is based on a more or less complete, i.e. parametric or semi-parametric modelling of both the procedure of selecting the participants and the process that determines the outcome. A disadvantage of these methods is that some technical assumptions regarding error terms and functional forms are required that do not always have a behavioural background and might lead to biased results if not correct. 
More recently non-parametric identifying assumptions and corresponding nonparametric estimation methods are used. Due to the fact that the coArb represents a large and informative pool of comparison and participating observations we will use a non-parametric evaluation approach in the following. With respect to estimation, matching methods are used (Heckman, Ichimura and Todd, 1998). "Matched sampling is a method for selecting units from a large reservoir of potential comparisons to produce a comparison group of modest size in which the distribution of covariates is similar to the distribution in the treated group" (Rosenbaum and Rubin, 1983: 48). In other words, matching can be referred to as a method that selects those people from a group of potential comparison observations who match the participants as closely as possible in terms of the variables driving the selection process.

\subsection{Econometrics}

The central question of our analysis is the causal effect of participation in NPT on the later employment status of the $T W$. The concept of the causal effect was formulated by Rubin (1974), who put it this way: "The causal effect of a measure for a specific person is the difference between the likely outcome of a person's participation in a measure and the likely outcome of a person's non-participation." (Rubin 1974: 689). The latter is not observable, as a person cannot be participant and non-participant at the same time. Under certain conditions, to be explained in the following, the average causal effect of the programme on the people who have actually participated in the programme $\left(\theta^{0}\right)$ can be calculated. The average causal effect can be expressed in the following way:

$\theta^{0}:=E\left(Y^{t}-Y^{n} \mid S=1\right)=E\left(Y^{t} \mid S=1\right)-E\left(Y^{n} \mid S=1\right)$,

whereas $E$ stands for the expectation operator and $S$ is an indicator variable for the participation status that is one for the participants and zero for the non-participants. $Y^{t}\left(Y^{n}\right)$ measures the employment status after a participation (non-participation) in the programme. $Y^{t}$ and $Y^{n}$ are also referred to as potential outcomes because they are defined independently of the individuals realised state. The use of the concept of potential outcomes takes into account the above mentioned impossibility to observe people both as participants and non-participants ( $Y^{n}$ can never be observed for participants, $Y^{t}$ can never be observed for non-participants).

The difficulty of determining the average causal effect from Equation (1) comes from the problems of identifying $E\left(Y^{n} \mid S=1\right)$, as $Y^{n}$ cannot be observed for participants; in contrast, $E\left(Y^{t} \mid S=1\right)$ can be estimated as arithmetic average of the various employment states of the participants after the programme. In the case of an experiment in which the access to a programme is regulated within the group of 
potentially entitled people by means of a random selection mechanism, the group of entitled non-participants $(S=0)$ could be used to estimate $E\left(Y^{n} \mid S=1\right)$. It is already clear from Table 2 that participants and non-participants differ in a systematic manner. Hence, we expect that $E\left(Y^{n} \mid S=1\right) \neq E\left(Y^{n} \mid S=0\right)$, meaning that $E\left(Y^{n} \mid S=1\right)$ cannot be estimated unbiasedly as arithmetic average from the employment status of non-participants observed after the programme.

Instead of assuming random participation like in an experiment the conditional independence assumption (CIA), meaning that participation and potential outcome are independent for individuals with the same set of characteristics $(X=x)$, is more attractive (Rubin 1977, cf. Equation 2).

$Y^{n} \perp S \mid X=x$.

CIA is only plausible if all important variables influencing $Y^{n}$ and $S$ are known and observed. For this reason an empirical analysis requires both a detailed knowledge on the participation process and sufficiently informative data. In our view, the coArb represents data that contain all relevant information either in direct or in indirect form and ensures that CIA holds. If CIA is correct, the equality $E\left(Y^{n} \mid S=1, X=x\right)=E\left(Y^{n} \mid S=0, X=x\right)$ holds. This means that, by using a group of nonparticipants whose distribution of exogenous variables does not differ from the one of the group of participants, $E\left(Y^{n} \mid S=1\right)$ can be consistently estimated, allowing a determination of the average causal effect of the programme.

To ensure the correctness of CIA in general a large number of exogenous variables is necessary. As a consequence $X$ has a high dimension, which means that a nonparametric estimate of $E\left(Y^{n} \mid S=1\right)$ becomes much more difficult. In order to avoid this dimensionality problem, the vector $x$ can be condensed to a scalar measure, the so-called propensity score. The propensity score $(p(x))$ is defined as the probability of participating in a programme conditional on $X(p(x)=P(S=1 \mid X=x))$. Rosenbaum and Rubin (1983) show that if CIA is valid, then conditioning on the propensity score is sufficient to guarantee the statistical independence between potential outcome and participation status.

The disadvantage of the propensity score is that it is not available as a variable in the data and thus has to be estimated. Since conditioning on $p(x)$ as well as on $x$ leads to conditional independence, it is clear that conditioning on terms like $(p(x), f(x))$ (balancing scores) is also sufficient, whatever the form of the function $f($. is. In practise $f($.) is formed in a way that some components of $X$ are excluded. In econometric applications - and thus also in the context of this analysis - mostly balancing scores are used which are such a mixture. 


\subsection{Preselection}

For economical reasons it was not possible to reorganise and process the individual employment histories available in the coArb databases, which were not encoded but had the form of plain texts, for all the 144,000 unemployed. Instead a sample had to be selected that could be processed, but which was at the same time big enough to enable a high matching quality. The goal of the preselection process was to find 15 comparison observations for each participant based on a reduced information set. The preselection was based on a simple matching procedure. A probit model for participation in the programme was estimated for calculating the participation probability based on all potential comparison observations plus the 134 TWS suitable for evaluation. The first column of Table 2 contains the variables used in this step. The following variables are significant at the $5 \%$ level:

- Age;

- Sex;

- Employment office district;

- Severe disablement;

- Occupation in the last employment relationship;

- Relocated expatriate from Eastern Europe.

In the next step those persons were selected as potential comparisons who are identical to the respective participant with respect to the values of the above listed significant variables. For participants for whom less than 15 "identical" comparison persons are available in the data the missing observations were determined with the nearest-neighbour method. That is, those persons are selected who's propensity score shows the smallest absolute difference to the respective participant. ${ }^{12}$ After this, the employment histories of the 2010 selected comparisons are reorganised and processed according to a procedure presented in the Appendix. Thus, the sample, that is the basis for the subsequent analyses (in the following referred to as "data set 2 "), contains $134+2,010=2,144$ persons.

\subsection{Selection of the comparison group}

After the reconstruction of the employment histories, "data set 2" contains in addition to the variables used so far 61 time-related indicator variables for the

12 The pre-selection is not expected to create statistical independence between participation status and potential results for the group of non-participants. In this phase of the analysis, the $C I A$ cannot be fulfilled, as the information from the employment histories are not available yet. 
analysis of the causal reintegration effect for each of the following events in the employment histories:

1. Times of unemployment;

2. Occupation during employment, differentiated according to 5 categories;

3. Education, differentiated according to school, apprenticeship, vocational school, technical school, university;

4. Participation in $A L M P$, differentiated according to further education, reeducation, rehabilitation and work creation programmes ("Arbeitsbeschaffungsmaßnahmen"), but without $N P T$;

5. Entry into and time in the NPT.

6. Periods without record in the $c o A r b$;

7. Illness;

8. Service in the armed forces, periods in social services;

9. Imprisonment;

10. Periods prior to the recording of the employment history by the employment office.

Moreover, variables for the frequency of the first and second failure to report to the employment office ("Meldeversäumnisse") of the years 1994, 1995 and 1996 as well as for the highest finished vocational training are available.

The detailed information on the employment history are partly aggregated to reduce the number of variables: In the case of unemployment, the periods 12/31/89 12/31/92, 01/01/93 - 12/31/93, 01/01/94 - 08/31/94, 09/01/94 - 02/28/95, 03/01/95 $-08 / 31 / 95,09 / 01 / 95-11 / 30 / 95$ and $12 / 01 / 95-02 / 29 / 96$ are chosen, taking into account the changing distances between reference dates. Employment, education, participation in a programme of the active labour market policy and times without record are treated the same way. The variables army service and illness are coded less meticulously due to their less frequent occurrence $(12 / 31 / 89-12 / 31 / 93$, $01 / 01 / 94-08 / 31 / 95$ and 09/01/95 - 02/29/96). The variables for imprisonment are reduced to one single indicator variable stating whether the respective person was imprisoned between the $12 / 13 / 89$ and the $02 / 29 / 96$ at least one time or not.

The employment history variables are defined relatively to the entry into the programme. Regarding the participation in a programme and its result, the employment status immediately before the start of the programme is important. In case of different starting dates, there is no uniform equivalent to the employment status one, two, three or more periods before the programme for a comparison person. An equivalent can be defined only relative to a specific participant or group of participants with the same starting point. 
All factors that are independent of the start of the programme belong to the group of the time-invariant variables. These are the variables from Table 2 and the newly created variables of the employment history. Among the time-variant variables range those events in the employment history that are defined relatively to the beginning of the programme by the participants. The inclusion of these time-variant variables increases the complexity of the analysis. However, this group of variables improves the matching quality substantially, as the comparisons are now selected in such a way that they also have a comparable employment history immediately before the beginning.

Lechner (1999b) proposed a method that is based on a separation of the components of the propensity score in time-invariant and time-variant variables. In the first step, the probability of participation is estimated on the basis of time-invariant variables. In a second step, the estimated (partial) propensity score is used together with the time-variant variables and possibly a vector of time-invariant variables already included in the partial propensity score, to determine a distance measure - the socalled "Mahalanobis-distance" - between a randomly selected participant and all non-participants. The non-participant with the smallest Mahalanobis-distance is stored in a new file together with the participant (matched pair), and both are removed from the original file. The second step is repeated until no participants are left in the original file.

\section{Step 1: Estimation of the propensity score using the time-invariant variables only}

On the basis of "data set 2" a probit model for the participation probability was estimated. For this purpose, all time-invariant variables are available. The variables involved for the final specification are depicted in Table 3 (numbers $1-22,24$ $30)$. Variables with coefficients significant at the $5 \%$ level, are marked with an "**". Due to the pre-selection it is only to a very limited extent possible to infer the determinants of participation in NPT from the coefficient estimates. Hence, these estimates are not presented. The probit model was tested against omitted variables, heteroscedasticity, and non-normality. There were no hints on possible misspecifications.

The matching algorithm presented in the next step can only be successful if the joint distribution of these variables between the two groups shows a sufficiently large overlap. Figure 3 shows the absolute frequencies of the propensity score for the group of participants (solid line) and the potential comparison group (dotted line). With the exception of few observations at the right margin of the distribution, the participants are covered completely by the comparison observations. 
In this step, pairs of participants and comparisons are matched that are as similar to each other as possible concerning all relevant variables. For this purpose, participant $i$ is selected randomly from the $N^{t}$ participants. Then, in relation to the individual date of joining the NPTA, the time-variant variables are calculated for all potential comparison observations. This allows a calculation of the distance to the participant according to the formula $d(j, i)=\left(v_{j} \hat{\beta}_{N}, m_{j}, u_{j}\right)^{\prime}-\left(v_{i} \hat{\beta}_{N}, m_{i}, u_{i}\right)^{\prime}$ for each comparison person $j$, with $v \hat{\beta}_{N}$ being the index of the propensity score estimated by the probit model, $m_{j}$ the vector of the time-variant variables and $u_{j}$ the vector of the time-invariant variables for each comparison person $j$. The variables of the participant are indexed with $i$.

\section{Figure 3: Distribution of $v \hat{\beta}_{N}$ for participants and comparisons}

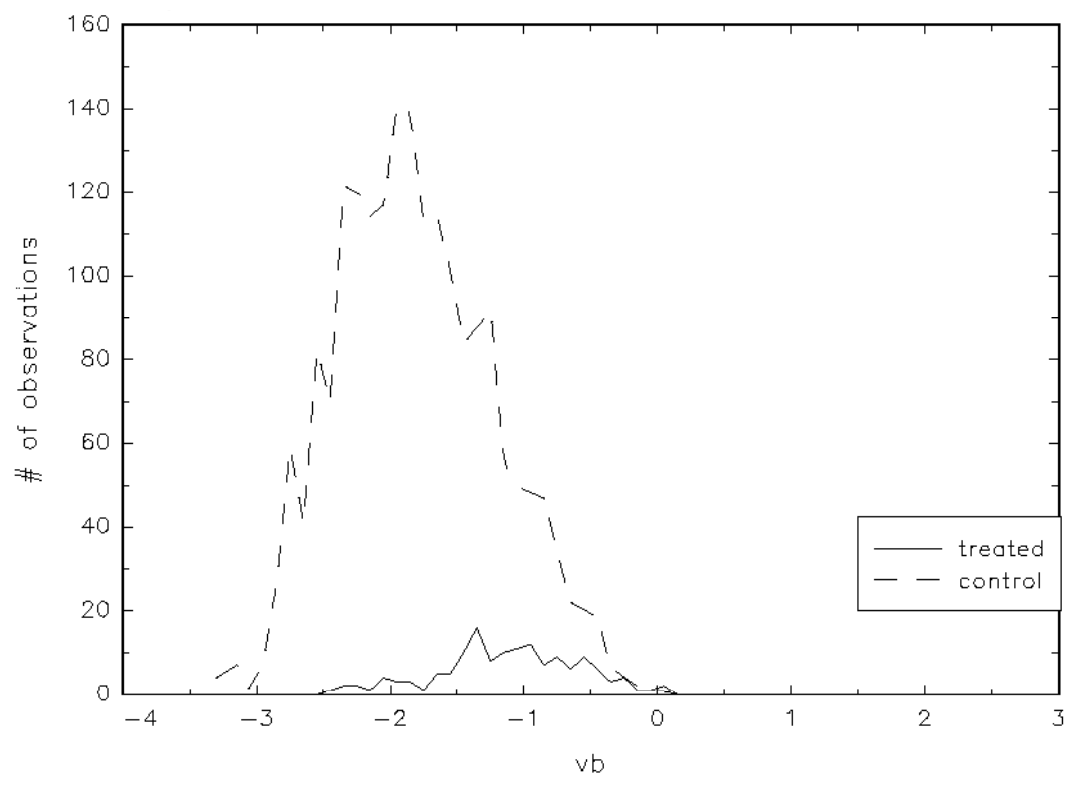

Note: \#=number of observations, $v \hat{\beta}_{N}:$ index of the propensity score.

Step 2: Matching on the basis of the partial propensity score, time-variant variables and selected time-invariant variables

Now the person is selected from the pool of all potential comparisons who has the smallest Mahalanobis-distance $m(j, i)=d(j, i)^{\prime} W d(j, i)$ to the participant $i$, with $W$ being the inverse of the covariance matrix of $\left(v \hat{\beta}_{N}, m, u\right)^{\prime}$ calculated on the basis of all potential comparison observations. The comparison selected and the participant are stored in the new "data set 3", with the comparison person being given a new index $k(=i)$. The entire process is repeated until for each $N^{t}$ participants one comparison observation was found. 
Table 3: Comparison of selected time-invariant variables between participants and the comparison group after matching

\begin{tabular}{|c|c|c|c|c|c|c|c|}
\hline No. & $\begin{array}{c}\text { Variable } \\
\text { (2) }\end{array}$ & $\begin{array}{c}\text { Mean } \\
\text { TWs } \\
\text { (3) }\end{array}$ & $\begin{array}{c}\text { Mean } \\
\text { comp. } \\
\text { group } \\
\text { (4) }\end{array}$ & $\begin{array}{c}\text { Bias } \\
\text { (3)-(4) } \\
\\
(5)\end{array}$ & $\begin{array}{c}\text { Bias in } \\
\% \\
(6)\end{array}$ & $\begin{array}{c}\text { P-value } \\
\text { in \%** } \\
\text { (V. 1) } \\
\text { (7) }\end{array}$ & $\begin{array}{c}\text { P-value } \\
\text { in } \% \text { ** } \\
\text { (V. 2) } \\
\text { (8) }\end{array}$ \\
\hline 1 & Gender (male) & 0.776 & 0.739 & 0.037 & 8.7 & 48 & 30 \\
\hline 2 & Impaired health influencing the reintegration success & 0.119 & 0.127 & -0.007 & -2.3 & 85 & 82 \\
\hline 3 & Relocated expatriate from Eastern Europe & 0.127 & 0.142 & -0.015 & -4.4 & 72 & 64 \\
\hline 4 & Never started a vocational education & 0.403 & 0.418 & -0.015 & -3.0 & 80 & 81 \\
\hline 5 & Vocational education started but not completed & 0.127 & 0.149 & -0.022 & -6.5 & 60 & 58 \\
\hline $6^{*}$ & $\begin{array}{l}\text { Registered with the employment office district of } \\
\text { Bad Kreuznach }\end{array}$ & 0.134 & 0.127 & 0.007 & 2.2 & 86 & 74 \\
\hline $7^{*}$ & $\begin{array}{l}\text { Registered with the employment office district of } \\
\text { Trier }\end{array}$ & 0.224 & 0.201 & 0.022 & 5.5 & 66 & 26 \\
\hline $8^{*}$ & $\begin{array}{l}\text { Impaired health and registered with the labour head } \\
\text { office of Trier }\end{array}$ & 0.097 & 0.090 & 0.007 & 2.6 & 83 & 57 \\
\hline $9^{*}$ & Registered with the employment office of Speyer & 0.448 & 0.448 & 0.000 & 0.0 & 100 & 100 \\
\hline $10^{*}$ & $\begin{array}{l}\text { Registered with a head office of one of the employment } \\
\text { office districts }\end{array}$ & 0.425 & 0.418 & 0.007 & 1.5 & 90 & 84 \\
\hline $11^{*}$ & Reporting failure 1995 & 0.075 & 0.067 & 0.007 & 2.9 & 81 & 78 \\
\hline 12 & Unempl. duration 12/01/95 - 02/29/96 (in 1/2 months) & 4.403 & 4.687 & -0.284 & -12.3 & 32 & 9 \\
\hline $13^{*}$ & Unempl. duration 09/01/95 - 11/30/95 (in 1/2 mths.) & 3.731 & 3.866 & -0.134 & -5.1 & 68 & 56 \\
\hline $14^{*}$ & Unempl. duration 09/01/94 - 02/28/95 (in mths.) & 2.269 & 2.590 & -0.321 & -11.9 & 33 & 31 \\
\hline 15 & Unempl. duration 01/01/93 - 12/31/93 (in 1/2 yrs.) & 0.560 & 0.627 & -0.067 & -8.2 & 50 & 47 \\
\hline 16 & Unempl. duration 12/31/89 - 12/31/92 (in $1 / 2$ yrs.) & 1.000 & 0.963 & 0.037 & 2.0 & 87 & 86 \\
\hline 17 & Employment Duration 09/01/94 - 02/28/95 (in mths.) & 2.254 & 2.060 & 0.194 & 7.2 & 55 & 50 \\
\hline $18^{*}$ & $\begin{array}{l}\text { Empl. Duration as unskilled worker 09/01/94 - 02/28/95 } \\
\text { (in mths.) }\end{array}$ & 1.299 & 1.410 & -0.112 & -4.8 & 70 & 67 \\
\hline 19 & Education duration 12/01/95-02/29/96 (in 1/2 mths.) & 0.082 & 0.112 & -0.030 & -4.4 & 72 & 42 \\
\hline 20 & $\begin{array}{l}\text { Duration of non-availability of the unemployed to the } \\
\text { employment office } 12 / 01 / 95-02 / 29 / 96 \text { (in } 1 / 2 \text { mths.) }\end{array}$ & 0.291 & 0.291 & 0.000 & 0.0 & 100 & 100 \\
\hline $21^{*}$ & Duration of illness 01/01/94 - 08/31/95 (in mths.) & 0.336 & 0.425 & -0.090 & -6.7 & 58 & 57 \\
\hline $22^{*}$ & $\begin{array}{l}\text { Duration of participation in active labour market policy } \\
01 / 01 / 94-08 / 31 / 95 \text { (in mths.) }\end{array}$ & 0.567 & 0.515 & 0.052 & 3.1 & 80 & 76 \\
\hline 23 & Propensity score & -1.125 & -1.186 & 0.062 & 11.4 & 35 & 0.2 \\
\hline 24 & Age & 3.282 & 3.320 & -0.038 & -4.0 & 74 & 63 \\
\hline 25 & Marital status & 2.060 & 2.060 & 0.000 & 0.0 & 100 & 100 \\
\hline 26 & Number of children & 0.515 & 0.470 & 0.045 & 5.3 & 67 & 52 \\
\hline 27 & Severe disablement & 0.067 & 0.052 & 0.015 & 6.3 & 61 & 16 \\
\hline 28 & Vocational indicator (2-digit-level) & 52.28 & 52.65 & -0.366 & -1.6 & 89 & 84 \\
\hline 29 & Unemployed on $02 / 29 / 96$ & 0.791 & 0.821 & -0.030 & -7.5 & 54 & 25 \\
\hline 30 & Imprisonment & 0.030 & 0.022 & 0.007 & 4.7 & 70 & 32 \\
\hline
\end{tabular}

Source: coArb, own calculations.

Notes: *Influence of the variables on the propensity score is significant at the $5 \%$ level. ${ }^{*}$ Significance level for mutual t-test of the hypothesis that the mean differences in both groups are the same. Variables in bold print are used in the preselection and are included into the matching algorithm as well.

Matching is regarded as successful if the distributions of the relevant variables in the group of participants and the comparison group do not differ significantly. Here, this is the case for the means of both the time-invariant variables and the timevariant variables (see Tables 3 and 4). Table 3 contains the mean values of the timeinvariant variables for the group of the participants (column 3) and for the comparison group (column 4). Column 5 states the absolute and column 6 the 
relative differences of these means. The p-values of columns 7 and 8 indicate whether these deviations are significantly different from zero or not (see Lechner, 1999a). Overall the differences are rather small and not significantly different from zero. When looking at the propensity score as a summary measure a significant difference appears with respect to one of the tests, but note that a difference of estimated quantities is tested without adjusting the distribution of the statistic accordingly. A more sensible test for the overall match quality is a Wald-test for all variables used to estimate the propensity score. This test cannot reject the hypothesis that the distribution of the 22 variables included have the same mean in both groups.

The variables in bold print given in Table 3 were directly included in the Matchingalgorithm. These are both variables which are also considered in the propensity score and variables which, being based on pre-selected data, have no longer an influence on participation, but clearly on the potential results. As far as it was not already mentioned in the context of the propensity score, for all variables the equality of means cannot be rejected.

Table 4 gives an indication of the quality of the matches with respect to the timevariant variables of the employment history. The differences of the proportions of employed people in both groups (column 4) before the programme are not significant. Since the comparison group and the programme participants do not differ significantly with respect to $X$, we conclude that the causal effect can be consistently estimated by comparing employment histories of both groups after $N P T$.

Table 4: The pre-programme history with respect to employment in per cent points

\begin{tabular}{cccccc}
\hline $\begin{array}{c}\text { Half-months } \\
\text { before } \\
\text { programme }\end{array}$ & $\begin{array}{c}\hat{E}\left(Y^{t} \mid S=1\right) \\
(T W s)\end{array}$ & $\begin{array}{c}\hat{E}\left(Y^{n} \mid S=1\right) \\
\text { (comparison group) }\end{array}$ & $\begin{array}{c}\hat{\theta}_{N} \\
(2)-(3)\end{array}$ & $\begin{array}{c}\text { P-value } \\
\text { in \% }\end{array}$ & $\begin{array}{c}\text { Number of } \\
\text { matched pairs }\end{array}$ \\
\hline-13 & $(2)$ & $(3)$ & $(4)$ & $(5)$ & $(6)$ \\
-12 & 23.1 & 14.2 & 9.0 & 5.9 & 134 \\
-11 & 23.1 & 16.4 & 6.7 & 17 & 134 \\
-10 & 19.4 & 17.2 & 2.2 & 64 & 134 \\
-9 & 18.7 & 16.4 & 2.2 & 63 & 134 \\
-8 & 17.2 & 13.4 & 3.7 & 40 & 134 \\
-7 & 17.2 & 11.9 & 5.2 & 23 & 134 \\
-6 & 14.2 & 10.4 & 3.7 & 35 & 134 \\
-5 & 14.2 & 11.2 & 3.0 & 46 & 134 \\
-4 & 14.2 & 10.4 & 3.7 & 35 & 134 \\
-3 & 10.4 & 9.0 & 1.5 & 68 & 134 \\
-2 & 10.4 & 9.0 & 1.5 & 68 & 134 \\
-1 & 11.9 & 8.2 & 3.7 & 31 & 134 \\
\hline
\end{tabular}

Source: Own calculations.

Note: P-values for the t-test of the hypothesis that the difference is zero. 


\section{Evaluation results}

Success of the programme refers to the transition of the $T W$ into the first labour market after the stay with the NPTA has ended. We do not regard the very stay with the agency as success, because the objective laid out in the GPTA is the reintegration of unemployed into the first labour market and thus creates a clear hierarchy as to which of these two forms of employment should be preferred. Success is calculated as the difference between the proportions of the participant and comparison group that are employed after the programme.

This difference is calculated for different temporary distances to the end of the programme until 10 half-months (Table 5). There is not a sufficiently long period or a sufficient number of observations available to assess the longer-term reintegration effects of NPT (from Table 5, column 6 it becomes obvious that 10 half-months after the end of the programme only 38 of the initially 134 persons were left). Furthermore aggregate effects on the reintegration success into the primary labour market are calculated (Table 6).

Table 5: Period effects on reintegration success into the primary labour market in per cent points

\begin{tabular}{cccccc}
\hline $\begin{array}{c}\text { Half-months } \\
\text { after } \\
\text { programme }\end{array}$ & $\begin{array}{c}\hat{E}\left(Y^{t} \mid S=1\right)(T \\
W s)\end{array}$ & $\begin{array}{c}\hat{E}\left(Y^{n} \mid S=1\right) \\
\text { (comparis. group) }\end{array}$ & $\begin{array}{c}\hat{\boldsymbol{\theta}}_{N} \\
(2)-(3)\end{array}$ & $\begin{array}{c}\text { P-value } \\
\text { in \% }\end{array}$ & $\begin{array}{c}\text { Number of } \\
\text { matched pairs }\end{array}$ \\
\hline 1 & $(2)$ & $(3)$ & $(4)$ & $(5)$ & $(6)$ \\
\hline 2 & 18.7 & 11.9 & 6.7 & 13 & 134 \\
3 & 23.0 & 11.5 & $\mathbf{1 1 . 5}$ & 1.7 & 122 \\
4 & 25.5 & 11.8 & $\mathbf{1 3 . 6}$ & 0.8 & 110 \\
5 & 27.4 & 11.3 & $\mathbf{1 6 . 0}$ & 0.3 & 106 \\
6 & 27.0 & 13.0 & $\mathbf{1 4 . 0}$ & 1.2 & 100 \\
7 & 28.1 & 14.6 & $\mathbf{1 3 . 5}$ & 2.1 & 96 \\
8 & 26.7 & 13.3 & $\mathbf{1 3 . 3}$ & 4.0 & 75 \\
9 & 26.4 & 12.5 & $\mathbf{1 3 . 9}$ & 3.4 & 72 \\
10 & 27.3 & 12.7 & 14.5 & 5.5 & 55 \\
\hline
\end{tabular}

Note: Effects that are significant at the $5 \%$ level are in bold letters. Reintegration success is measured as employment in the first labour market. See also note of Table 4.

According to our method for coding the employment histories the distance is measured in steps of half-months. The earliest effect is determined one half-month, the latest effect 10 half-months after the end of the programme. Table 5, column 2 contains the proportions of the $T W S$ who after completing their employment with a NPTA entered the first labour market. Column 3, Table 5 shows the respective values for the comparison group. The estimates of the causal effects of the programme are given in column 4 . Column 5 contains the significance levels of the t-tests of the hypothesis that the causal effects equal zero. The respective columns 2 , 3 and 4 of Table 6 show the expected total number of half-month of employment 
between the end of the programme and period $T$. Column 4 contains the causal effect in terms of the expected length of employment due to NPT.

The percentage of those former TWs having entered the first labour market (Table 5, column 2) lies above the comparison group (column 3, Table 5) in all the ten points of time examined. One half-month after the end of the measure, the proportion of the reintegrated $T W S$ amounts to $18.7 \%$, while it is only $11.9 \%$ for the comparison group. After five half-months the percentage rises significantly for both groups, but for the $T W s(27 \%)$ it is again considerably higher than for the comparison group (13\%). Also 10 half-months after the end of the programme, TWs are more frequently employed than the comparable non-participants $(28.9 \%$ compared to $15.8 \%)$. The greatest effect (16\%) occurs four half-months after the end of the programme. With a p-value of $0.3 \%$, the effect is statistically significant. With the exception of the first and the last two time points the estimated effects are all significant at the $5 \%$ level.

The aggregate effects on the reintegration success into the primary labour market are positive and rise up to an amount of 1.1 half-months after eight time periods. While a member of the comparison group has an expected stay of 0.9 half-months in the first four months after leaving the NPTA a participants has an expected stay of 2 half-months (Table 6). This effect is statistically significant at the $5 \%$ level.

Table 6: Aggregate effects on reintegration success into the primary labour market

\begin{tabular}{cccccc}
\hline $\begin{array}{c}\text { Half-months } \\
\text { after } \\
\text { programme }\end{array}$ & $\begin{array}{c}\hat{E}\left(Y^{t} \mid S=1\right) \\
(T W s)\end{array}$ & $\begin{array}{c}\hat{E}\left(Y^{n} \mid S=1\right) \text { (compar } \\
\text { is. group) }\end{array}$ & $\begin{array}{c}\hat{\boldsymbol{\theta}}_{N} \\
(2)-(3)\end{array}$ & $\begin{array}{c}\text { P-value } \\
\text { in \% }\end{array}$ & $\begin{array}{c}\text { Number of } \\
\text { matched pairs }\end{array}$ \\
\hline 1 (1) & $(2)$ & $(3)$ & $(4)$ & $(5)$ & $(6)$ \\
2 & 0.19 & 0.12 & 0.07 & 13 & 134 \\
3 & 0.43 & 0.22 & $\mathbf{0 . 2 1}$ & 1.7 & 122 \\
4 & 0.68 & 0.34 & $\mathbf{0 . 3 4}$ & 0.8 & 110 \\
5 & 0.95 & 0.46 & $\mathbf{0 . 4 9}$ & 0.3 & 106 \\
6 & 1.24 & 0.58 & $\mathbf{0 . 6 6}$ & 1.2 & 100 \\
7 & 1.51 & 0.70 & $\mathbf{0 . 8 1}$ & 2.1 & 96 \\
8 & 1.65 & 0.83 & $\mathbf{0 . 8 3}$ & 4.0 & 75 \\
9 & 2.00 & 0.90 & $\mathbf{1 . 1 0}$ & 3.4 & 72 \\
10 & 2.02 & 1.07 & 0.95 & 5.5 & 55 \\
\hline
\end{tabular}

Note: The outcome in period $T$ is measured as the sum of outcomes of periods 1 to $T$ as defined in the previous tables. This quantity is estimated using only individuals observed in all periods 1 to $T$. The estimated effect can be interpreted as the expected total number of half-months of employment between the end of the programme and period $T$ that are due to the programmes. See notes of Tables 4 and 5.

As a central result it can be stated that despite its low absolute reintegration rate compared to the rate of $46.5 \%$ that has been measured for public training programmes (see Blaschke and Nagel, 1995), the NPT can be attributed a certain success with the reintegration of problem groups into the primary labour market. On 
average, the effect of participation for the first five months after the end of the programme is about $13 \%$ compared to non-participation. Furthermore unemployed participating in the programme have an expected aggregated stay in the first labour market more than half a month longer than non-participants. That is in the first four months after participation the effect of NPT is 1.1 half-months. The relative high intensive supervision of the $T W S$ as well as the presumably more direct addressing of enterprises by the agencies in comparison with the FES has been particularly successful in the tight labour market for problem groups. By the employment of unemployed and their hiring out, many $T W s$ get the opportunity to create a good impression with a potential future employer. Another explanation for the relative success is that NPTAs possess especially good information on employment opportunities for long-term unemployed.

\section{Concluding remarks}

The aim of the study was to assess the direct impact of publicly subsidised NPTAs on the entry success of unemployed into the primary labour market, part of them belonging to the group of hard-to-place persons.

GPTA was a small programme both from the money spend and from the impacts it had. It did not change the labour market perspectives on the group of the roughly 50,000 hard-to-place unemployed in Rhineland-Palatinate much. However, it had a positive net impact at the local micro level in that it improved the situation of roughly 100 unemployed which otherwise not would have incurred.

For a comprehensive evaluation of the GPTA programme of the FES more extensive analyses would be required that should include other direct impacts (for example on earnings; on longer term impacts; on participants reduced use of social welfare etc.), indirect impacts (for example on non-participants and through the forgone use of the money invested) and the longer perspective of the NPTAs (none was out of business in April 1997) in the evaluation. Another future research topic would be a comparison of temp agencies with alternative programmes for the reintegration of unemployed, such as programmes of further or re-education or wage subsidies, which are in fact in wider use or comparison with the recently introduced job placements premia according to the so-called "Maatwerk"-method, where commercial agencies get premia for a successful placement of hard-to-place persons. Such comparisons based on suitable comparison groups can contribute to improve the understanding of the effectiveness of alternative programmes of active labour market policy. 


\section{Appendix}

Table A1: Example of a hypothetic employment history in the coArb

\begin{tabular}{|c|c|c|c|c|c|}
\hline $\begin{array}{l}\text { No. of } \\
\text { entry }\end{array}$ & From & To & Code & Event & Position or other entries \\
\hline 1 & 25 Nov 96 & & $\bar{A}$ & $\begin{array}{l}\text { Alo-Meld. }{ }^{13} \text {, Aldo-WB- } \\
\text { Antragis }\end{array}$ & \\
\hline 2 & 12 Nov 96 & 24 Nov 96 & & ont5 & \\
\hline 3 & 24 Okt 96 & 11 Nov 96 & & $\mathrm{Fa} \cdot{ }^{16} \mathrm{XXX}$ & \\
\hline 4 & 01 Oct 96 & 23 Oct 96 & \multicolumn{3}{|c|}{ In NPTA } \\
\hline 5 & 08 Apr 96 & 30 Sep 96 & & Fa. XXX & Warehouse worker \\
\hline 6 & 01 Apr 96 & 05 Apr 96 & & Fa. XXX & $\begin{array}{l}\text { Unskilled construction } \\
\text { worker }\end{array}$ \\
\hline 7 & $14 \mathrm{Dec} 95$ & & A & Alo-meld. & WB-Antrag 17 \\
\hline 8 & 06 Dec 95 & & A & Alo-Meldung & WB-Antragstellung \\
\hline 9 & 23 Nov 95 & $13 \operatorname{Dec} 95$ & & krank geschrieben 118 & \\
\hline 10 & Jun 95 & 20 Nov 95 & & $X X X$ & $\begin{array}{l}\text { forklifter, production } \\
\text { hand }\end{array}$ \\
\hline 11 & 30 Oct 95 & & & $\begin{array}{c}\text { 1.MV } 19301095 / 2 . M V \\
091195\end{array}$ & \\
\hline 12 & 03 Apr 95 & & A & Alo-Meldung & WB-Antragstellung \\
\hline 13 & 15 Mar 95 & 31 Mar 95 & & krank $^{\text {k0 }}$ & \\
\hline 14 & 01 Sep 94 & 15 Mar 95 & + & Fa. XXX wurde am & 210195 weiterbesch.[21] \\
\hline 15 & 27 Jan 95 & & & $\begin{array}{c}\text { 1.MV } 270195 / 2 . M V \\
090295\end{array}$ & \\
\hline 16 & 26 Jan 95 & & A & Alo-meld. WB-Antrag & \\
\hline 17 & 21 Jan 95 & 25 Jan 95 & & o.N. & \\
\hline 18 & 01 Sep 94 & 20 Jan 95 & + & Fa. XXX & Locksmith \\
\hline 19 & $01 \mathrm{Jul} 94$ & & A & $\begin{array}{l}\text { Alo-Meldg. } 130694 \text { Alg- } \\
\text { Antrag }\end{array}$ & \\
\hline 20 & $01 \mathrm{Jul} 93$ & 30 Jun 94 & + & Fa. XXX & Warehouse worker \\
\hline 21 & 91 & 93 & & Fa. XXX & Resocialisation \\
\hline 22 & 88 & 90 & & Fa. XXX & Metal industry \\
\hline
\end{tabular}

Source: coArb database; note: The entries in the table were made up by the ZEW after really existing employment histories in the coArb; $\mathrm{WB}=\mathrm{Weiterbildung,} \mathrm{MV}=$ Meldeversäumnis, o.N. ohne Nachweis.

13 Registered unemployed.

14 Application for general further education.

15 No records.

${ }^{16}$ Company.

17 Application for general further education.

18 Sick leave.

${ }^{19}$ Reporting failure.

${ }^{20}$ Ill.

21 Was re-employed on 21/01/1995. 
Table A2: Example of a coded employment history

\begin{tabular}{|c|c|c|c|c|c|c|}
\hline $\begin{array}{l}\text { Half- } \\
\text { month }\end{array}$ & $\begin{array}{l}\text { Reference date/ } \\
\text { half-months }\end{array}$ & Code* & $\begin{array}{l}\text { Reference date/ } \\
\text { months }\end{array}$ & Code $^{*}$ & $\begin{array}{l}\text { Reference date/ } \\
\text { half-months }\end{array}$ & Code $^{*}$ \\
\hline 20 & $31 \mathrm{Dec} 96$ & 0 & $31 \mathrm{Jul} 95$ & 11 & 30 Jun 93 & 11 \\
\hline 19 & 16 Dec 96 & 0 & 30 Jun 95 & 11 & $31 \mathrm{Dec} 92$ & 5 \\
\hline 18 & 30 Nov 96 & 0 & 31 May 95 & 0 & 30 Jun 92 & 5 \\
\hline 17 & 16 Nov 96 & 91 & 30 Apr 95 & 0 & $31 \mathrm{Dec} 91$ & 5 \\
\hline 16 & 31 Oct 96 & 11 & 31 Mar 95 & 93 & 30 Jun 91 & 5 \\
\hline 15 & 16 Oct 96 & 71 & 28 Feb 95 & 131 & 31 Dec 90 & 11 \\
\hline 14 & 30 Sep 96 & 0 & 31 Jan 95 & 131 & 30 Jun 90 & 11 \\
\hline 13 & 16 Sep 96 & 11 & $31 \mathrm{Dec} 94$ & 131 & $31 \mathrm{Dec} 89$ & 11 \\
\hline 12 & 31 Aug 96 & 11 & 30 Nov 94 & 131 & & \\
\hline 11 & 16 Aug 96 & 11 & 31 Oct 94 & 131 & & \\
\hline 10 & 31 Jul 96 & 11 & 30 Sep 94 & 131 & & \\
\hline 9 & 16 Jul 96 & 11 & 31 Aug 94 & 0 & & \\
\hline 8 & 30 Jun 96 & 11 & 31 Jul 94 & 0 & & \\
\hline 7 & 16 Jun 96 & 11 & 30 Jun 94 & 11 & & \\
\hline 6 & 31 May 96 & 11 & 31 May 94 & 11 & & \\
\hline 5 & 16 May 96 & 11 & 30 Apr 94 & 11 & & \\
\hline 4 & 30 Apr 96 & 11 & 31 Mar 94 & 11 & & \\
\hline 3 & 16 Apr 96 & 11 & 28 Feb 94 & 11 & & \\
\hline 2 & 31 Mar 96 & 0 & 31 Jan 94 & 11 & & \\
\hline \multirow[t]{14}{*}{1} & 16 Mar 96 & 0 & 31 Dec 93 & 11 & & \\
\hline & 29 Feb 96 & 0 & & & & \\
\hline & 16 Feb 96 & 0 & & & & \\
\hline & 31 Jan 96 & 0 & & & & \\
\hline & 16 Jan 96 & 0 & & & & \\
\hline & 31 Dec 95 & 0 & & & & \\
\hline & 16 Dec 95 & 0 & & & & \\
\hline & 30 Nov 95 & 93 & & & & \\
\hline & 16 Nov 95 & 11 & & & & \\
\hline & 31 Oct 95 & 11 & & & & \\
\hline & 16 Oct 95 & 11 & & & & \\
\hline & 30 Sep 95 & 11 & & & & \\
\hline & 16 Sep 95 & 11 & & & & \\
\hline & 31 Aug 95 & 11 & & & & \\
\hline
\end{tabular}

Source: Own representation based on the coArb and the hypothetic employment history of person xxx. ${ }^{*} 0=$ unemployment, $91=$ no records, $1 \ldots=$ employment in the first labour market differentiated according to the skill level of the activity, $71=$ NPTA, $93=$ illness, $5=$ rehabilitation. 


\section{Literature}

Almus, M., Egeln, J., Lechner, M., Pfeiffer, F., Spengler, H. (1999): "Wirkungen gemeinnütziger Arbeitnehmerüberlassung in Rheinland-Pfalz". BeitrAB 225, Nürnberg.

Blaschke, D., Nagel, E. (1995): "Beschäftigungssituation von Teilnehmern an AFGfinanzierter beruflicher Weiterbildung”. MittAB, Vol. 28, 195-213.

Bonnal, L., Fougère, D., Sérandon, A. (1994): "L'impact des dispositifs d'emploi sur le devenir des jeunes chômeurs: une évaluation économétrique sur données longitudinales". Economie et Prévisions, 115 (4), 1-28.

Bonnal, L., Fougère, D., Sérandon, A. (1997): "Evaluating the Impact of French Employment Policies on Individual Labour Market Histories". Review of Economic Studies, 64, 683-713.

De Koning, J., Denys, J., Walwei, U. (1998): "Deregulation in placement services: a comparative study for eight EU countries (Draft)". Netherland Economic Institute, Rotterdam.

Eichler, M., Lechner, M. (1998): “An Evaluation of Public Employment Programmes in the East German State of Sachsen-Anhalt". Discussion Paper 9815, University of St. Gallen.

Erhel, C., Gautié, J., Gazier, B., Morel, S. (1996): “Job Opportunities for the Hardto-place”. In: Schmid, G., O’Reilly, J., Schömann, K. (eds.): International Handbook of Labour Market Policy and Evaluation. Cheltenham: Edward Elgar, 277-307.

Friedlander, D., Greenberg, D. H., Robins, P. K. (1997): "Evaluating Government Training Programs for the Economically Disadvantaged". Journal of Economic Literature, 35, 1809-1855.

Heckman, J. J., Ichimura, H., Todd, P. (1998): "Matching as an Econometric Evaluation Estimator". Review of Economic Studies, 65, 261-294.

Heckman, J. J., LaLonde, R., Smith, J. A. (1999): "The Economics and Econometrics of Active Labor Market Programs". Forthcoming in: Ashenfelter, O., Card, D. (Ed.): The Handbook of Labor Economics, Volume III.

Kraus, F., Puhani, P., Steiner, V. (1997): "Employment effects of publically financed training programs - the East German experience". Discussion Paper, No. 97-33, Zentrum für Europäische Wirtschaftsforschung, Mannheim. 
Lechner, M. (1999a): "An Evaluation of Public Sector Sponsored Continuous Vocational Training Programs in East Germany". Discussion Paper 9901, University of St. Gallen.

Lechner, M. (1999b): "Earnings and Employment Effects of Continuous Off-theJob Training in East Germany after Unification". Journal of Business \& Economic Statistics, 17, 74-90.

OECD (1996): The OECD Jobs Strategy. Enhancing the effectiveness of active labour market policies. Paris.

Rosenbaum, P. R., Rubin, D. B. (1983): "The Central Role of the Propensity Score in Observational Studies for Casual Effects", Biometrica, 70, 41-55.

Rubin, D. B. (1974): "Estimating Causal Effects of Treatments in Randomized and Nonrandomized Studies". Journal of Educational Psychology, 66, 688-701.

Rubin, D. B. (1977): “Assignment to Treatment Group on the Basis of a Covariate". Journal of Educational Statistics, 2, 1-26.

Vanselow, A., Weinkopf, C. (1997): "Wiedereingliederungsorientierte Arbeitnehmerüberlassung in der Bundesrepublik Deutschland - Ergebnisse einer schriftlichen Befragung”. Projektbericht, Nr. 1997-07, Institut Arbeit und Technik, Gelsenkirchen.

Walwei, U. (1996): "Improving Job-matching through Placement Services". In: Schmid, G., O’Reilly, J., Schömann, K. (eds.): International Handbook of Labour Market Policy and Evaluation. Cheltenham: Edward Elgar, 402-430.

Walwei, U. (1998): "Job Placement in Germany: Developments before and after Deregulation". IAB labour market research topics, Nürnberg. 